\title{
Laparoscopic versus open colorectal resection for cancer and polyps: a cost-effectiveness study
}

This article was published in the following Dove Press journal:

ClinicoEconomics and Outcomes Research

26 September 2014

Number of times this article has been viewed

\section{Jake Jordan' \\ Henry Dowson ${ }^{2}$ \\ Heather Gage ${ }^{3}$ \\ Daniel Jackson ${ }^{3}$ \\ Timothy Rockall ${ }^{4}$}

'Health Economics Research

Group, Brunel University, Uxbridge, Middlesex, England; ${ }^{2}$ Frimley Park

Hospital, Surrey, England; ${ }^{3}$ School of Economics, University of Surrey, Surrey, England; ${ }^{4}$ Royal Surrey County

Hospital, Surrey, England
Correspondence: Heather Gage School of Economics, University of Surrey, Staghill, Guildford, Surrey, GU2 $7 \mathrm{XH}$, England

Tel 44 |483 686948

Fax $44 \mid 483689548$

Email h.gage@surrey.ac.uk
Background: Available evidence that compares outcomes from laparoscopic and open surgery for colorectal cancer shows no difference in disease free or survival time, or in health-related quality of life outcomes, but does not capture the short term benefits of laparoscopic methods in the early postoperative period.

Aim: To explore the cost-effectiveness of laparoscopic colorectal surgery, compared to open methods, using quality of life data gathered in the first 6 weeks after surgery.

Methods: Participants were recruited in 2006-2007 in a district general hospital in the south of England; those with a diagnosis of cancer or polyps were included in the analysis. Quality of life data were collected using EQ-5D, on alternate days after surgery for 4 weeks. Costs per patient, from a National Health Service perspective (in British pounds, 2006) comprised the sum of operative, hospital, and community costs. Missing data were filled using multiple imputation methods. The difference in mean quality adjusted life years and costs between surgery groups were estimated simultaneously using a multivariate regression model applied to 20 imputed datasets. The probability that laparoscopic surgery is cost-effective compared to open surgery for a given societal willingness-to-pay threshold is illustrated using a cost-effectiveness acceptability curve.

Results: The sample comprised 68 laparoscopic and 27 open surgery patients. At 28 days, the incremental cost per quality adjusted life year gained from laparoscopic surgery was $£ 12,375$. At a societal willingness-to-pay of $£ 30,000$, the probability that laparoscopic surgery is costeffective, exceeds $65 \%$ (at $£ 20,000 \approx 60 \%$ ). In sensitivity analyses, laparoscopic surgery remained cost-effective compared to open surgery, provided it results in a saving $\geq £ 699$ in hospital bed days and takes no more than 8 minutes longer to perform.

Conclusion: The study provides formal evidence of the cost-effectiveness of laparoscopic approaches and supports current guidelines that promote use of laparoscopy where suitably trained surgeons are available.

Keywords: colorectal cancer, laparoscopy, cost-effectiveness, QALYs

\section{Introduction}

Within the British National Health Service (NHS), laparoscopic resection is recommended by the National Institute for Health and Care Excellence (NICE) as an alternative to open surgery for people with colorectal cancer for whom both methods would be considered suitable, and if performed by a trained surgeon. ${ }^{1} \mathrm{~A}$ health technology assessment suggested that laparoscopic surgery was associated with higher costs, but was no more effective than open surgery. Savings from shorter hospital stays after laparoscopic procedures did not fully offset higher operation costs and conversions to open methods due to complications. ${ }^{1}$ Research concludes that there is no significant 
difference in disease free or overall survival at 3 years, ${ }^{1,2}$ or in health-related quality of life outcomes. ${ }^{3-6}$ However, few studies capture the short term benefits of laparoscopic surgery in the early postoperative period. . $^{1,7}$

The technology assessment concluded that, at the $£ 30,000$ cost per quality adjusted life year (QALY) threshold, ${ }^{8}$ laparoscopic surgery would need to result in a gain of 0.009-0.010 QALY to be considered cost-effective, compared to open surgery. ${ }^{1,2} \mathrm{~A}$ study was undertaken to explore the QALY differences in the early postoperative recovery period, ${ }^{9}$ and costs. ${ }^{10}$ This paper reports the cost-effectiveness analysis that brings together the QALY and cost data for those patients who had a diagnosis of cancer or polyps. Helped by the National Training Programme for Laparoscopic Colorectal Surgery (LAPCO), the uptake of laparoscopic surgery has increased in NHS hospitals, but it is still used in the minority of cases (40\% in 2012). ${ }^{11}$ Providing evidence on cost-effectiveness may encourage increased training of surgeons and wider use of laparoscopic methods. ${ }^{12}$

\section{Methods}

\section{Participants}

Consecutive patients requiring elective colorectal resections (over 18 years, without endometriosis, able to give consent) in a district general hospital in south England were invited to join the study, 2006-2007. Patients were allocated to laparoscopic or open surgery by administrative staff, depending on availability of clinic appointments, or, in some cases, requests from referring general practitioners.

\section{Data collection}

Following informed consent, baseline demographic information (sex, age, operation type [right or left side resection], American Society of Anesthesiologists (ASA) physical status score) was collected pre-operatively. Patients were followed for 6 weeks after surgery. A micro-costing study gathered treatment costs (operative, in-hospital stay, community), in British pounds, 2006, as described in full elsewhere. ${ }^{10}$ Quality of life data were collected using EuroQol 5D-3L instrument (EQ-5D). The five domains (mobility, self-care, usual activities, pain/discomfort, anxiety/depression) are scored on three levels (1, no problem; 2 , some problem; 3 , serious/extreme problem/unable) giving a theoretical maximum of 243 different health states which are converted to single index utility values (range -0.59 for score 33333 to 1.0 [perfect health] for score 11111), using UK tariff tables. ${ }^{13-15}$ Participants were asked to complete EQ-5D on alternate days after surgery for 4 weeks, and at the end of the fifth and sixth week (total of
16 times), in a diary that was returned at the 6 week outpatient follow-up clinic appointment.

\section{Sample}

Among 201 patients (131 laparoscopic, 70 open) recruited, $129(64.2 \%)$ had a diagnosis of cancer or polyps (85 laparoscopic, 44 open). The sample was reduced to 98 (70 laparoscopic, 28 open) by exclusion of patients undergoing a rectal resection because such procedures (which typically result in higher costs and lower QALY due to requiring a stoma), ${ }^{7,10}$ were unevenly distributed between the groups $(n=15,17.6 \%$ laparoscopic; $n=16,36.4 \%$ open). A further three patients were lost because missing data were too extensive to be imputed. Hence, the final sample included in the analysis was 95 (68 laparoscopic, 27 open), of which 17 (18.0\%) had a diagnosis of polyps, rather than cancer; 14 (20.6\%) of laparoscopic procedures, 3 (11.1\%) of open.

\section{Analysis}

Data were imported into STATA12 (Stata Statistical Software, release 12; StataCorp LP, College Station, TX, USA). Baseline characteristics of groups were compared. Costs and quality of life data were assessed for missing data. Since it was found that a complete case analysis would reduce the sample to 43, and result in exclusion of some participants with complete EQ-5D or cost data, multiple imputation (Monte Carlo simulation) was used to generate missing values. ${ }^{16}$ It was not possible to impute stable quality of life estimates up to 42 days, so the analysis focused on the first 28 days after surgery (14 EQ-5D scores).

An area under the curve (AUC) method was employed to generate a QALY value for each patient. Differences in mean QALYs and costs between surgery groups were estimated simultaneously using a multivariate regression model applied to 20 imputed datasets with EQ-5D at baseline, sex, age, and operation type (left, right side) included as covariates. ASA score was strongly correlated with the EQ-5D baseline score and therefore not included as a covariate. A cost-effectiveness ellipse and cost-effectiveness acceptability curve (CEAC) were produced to indicate the probability that laparoscopic surgery is cost-effective compared to open for a given societal willingness-to-pay (WTP) threshold. Sensitivity analyses were performed.

\section{Ethical considerations}

A favorable ethical opinion was obtained prior to starting the research from the South West Surrey Local Research Ethics Committee (study 05/Q1909/74), and the hospital Research 
and Development Committee. All participants gave informed consent prior to inclusion in the study.

\section{Results}

There were no statistically significant differences between groups at baseline (Table 1). The multiple imputation regression estimates (Table 2) show the cost of the laparoscopic operations was $£ 1,037$ higher than open $(P<0.005)$, due to equipment costs; staff costs were $£ 190$ lower $(P=0.039)$ due to a shorter operating time (Table 3 ). The open group had a longer mean length of hospital stay (Table 3 ) and incurred $£ 897$ higher bed day costs $(P=0.007)$ compared to laparoscopic. Community costs were low in both groups. There was no significant difference in the total costs between the groups because the higher laparoscopic surgery costs were offset by shorter lengths of stay. Compared to those undergoing open surgery, patients in the laparoscopic group gained an average of 0.011207 QALYs over the first 28 days after surgery ( $95 \%$ confidence intervals 0.006 to 0.016 ) (Table 2 and Figure 1).

\section{Cost-effectiveness}

At 28 days, the overall incremental cost-effectiveness ratio (ICER), calculated as the difference in adjusted mean costs divided by the difference in adjusted mean QALYs, and showing the cost per QALY gained from laparoscopic, compared to open surgery, was $£ 12,375$. Uncertainty in the ICER point estimates are represented, using confidence intervals, on the cost-effectiveness plane (CEP) (Figure 2). The cost-effectiveness ellipse is centered in the top right quadrant, indicating that laparoscopic surgery is more costly and more effective than open. The confidence intervals of the ellipse overlap the bottom right quadrant where laparoscopic is dominant (less costly and more effective than open). The line bisecting the top right and lower left quadrants shows the threshold cost-effectiveness line, based on a WTP of $£ 20,000$. The point estimate ICER lies below this threshold, demonstrating laparoscopic surgery as cost-effective.

The CEAC illustrates the probability that laparoscopic treatment will be deemed cost-effective at different societal WTP per QALY gained (Figure 3). At 28 days, the CEAC indicates that, at WTP of $£ 30,000$, the probability that laparoscopic surgery will be cost-effective, compared to open methods, exceeds $65 \%$ (and this is also illustrated by the proportion of the $95 \%$ confidence interval below the threshold line in Figure 2). At a WTP of $£ 20,000$, the probability is approaching $60 \%$.

\section{Sensitivity analysis}

The costs of equipment and supplies, operative medical staff, hospital bed days, and community costs were varied independently of one another between the minimum and maximum values of their $95 \%$ confidence intervals whilst all other variables were held constant at their mean point estimates. At their lowest level, where costs were most favorable toward laparoscopic surgery, the resulting ICERs were all dominant in favor of the laparoscopic procedure. Where the differences in costs were considered at their highest (in favor of open), the result was less clear. With operative staff costs and community costs at their highest level, laparoscopic surgery still appeared cost-effective at

Table I Baseline comparison of groups

\begin{tabular}{|c|c|c|c|c|c|c|c|}
\hline \multirow[t]{2}{*}{ Characteristic } & \multicolumn{3}{|c|}{ Laparoscopic, $N=68$} & \multicolumn{3}{|c|}{ Open, $N=27$} & \multirow{2}{*}{$\begin{array}{l}\text { Significant } \\
\text { difference }\end{array}$} \\
\hline & $\mathbf{n}$ & $\%$ & & $\bar{n}$ & $\%$ & & \\
\hline \multicolumn{8}{|l|}{ Sex } \\
\hline Male & 35 & 51.5 & & 12 & 44.4 & & $P=0.66^{\wedge}$ \\
\hline Female & 33 & 48.5 & & 15 & 55.6 & & \\
\hline \multicolumn{8}{|l|}{ Operation type } \\
\hline Right & 32 & 47.1 & & 16 & 59.3 & & $P=0.18^{\wedge}$ \\
\hline \multirow[t]{2}{*}{ Left } & 36 & 52.9 & & II & 40.7 & & \\
\hline & $\mathbf{n}$ & Mean & SD & $\mathbf{n}$ & Mean & SD & \\
\hline \multicolumn{8}{|l|}{ Age } \\
\hline Years & 68 & 72.6 & II.4 & 27 & 71.9 & 10.6 & $P=0.66^{\#}$ \\
\hline \multicolumn{8}{|l|}{ ASA score } \\
\hline $1-3$ (worst) & 68 & 2.2 & 0.7 & 27 & 2.1 & 0.7 & $P=0.14^{\wedge}$ \\
\hline \multicolumn{8}{|l|}{ EQ-5D } \\
\hline-0.59 to 1.00 & 47 & 0.83 & 0.17 & 21 & 0.82 & 0.18 & $P=0.83^{\#}$ \\
\hline
\end{tabular}

Notes: 'Chi-square test; "Mann-Whitney $U$ test.

Abbreviations: ASA, American Society of Anesthesiologists; SD, standard deviation; EQ-5D, EuroQol 5 Dimension, 3 Level. 
Table 2 Cost $(\ell, 2006)$ and QALY differences between groups

\begin{tabular}{|c|c|c|c|c|c|c|c|}
\hline & \multicolumn{2}{|c|}{ Unadjusted group means } & \multicolumn{5}{|c|}{ Adjusted* group differences (laparoscopic - open) } \\
\hline & \multirow{2}{*}{$\begin{array}{l}\text { Lapar- } \\
\text { oscopic }\end{array}$} & \multirow[t]{2}{*}{ Open } & \multirow{2}{*}{$\begin{array}{l}\text { Mean } \\
\text { difference }\end{array}$} & \multirow{2}{*}{$\begin{array}{l}\text { Standard } \\
\text { error }\end{array}$} & \multirow[t]{2}{*}{$P$} & \multicolumn{2}{|c|}{$95 \%$ confidence interval } \\
\hline & & & & & & Lower & Upper \\
\hline \multicolumn{8}{|l|}{ Operation costs } \\
\hline Equipment, supplies & $|, 582.3|$ & 382.40 & $1,226.68$ & 121.48 & $<0.0005$ & 976.60 & $1,476.75$ \\
\hline Medical staff & 496.79 & 690.52 & -189.72 & 87.76 & 0.039 & -369.14 & -10.29 \\
\hline Total & $2,079.10$ & $1,072.92$ & $1,036.96$ & 166.36 & $<0.0005$ & 696.71 & I,377.2। \\
\hline \multicolumn{8}{|l|}{ Hospital } \\
\hline Bed days & $|, 582.5|$ & $2,486.76$ & -896.68 & 326.74 & 0.007 & $-|, 546.2|$ & -247.15 \\
\hline \multicolumn{8}{|l|}{ Community } \\
\hline GP, nurse, $A \& E$ etc & 124.74 & 127.77 & -1.58 & 27.30 & 0.954 & -55.87 & 52.70 \\
\hline Total costs & $3,786.35$ & $3,687.45$ & 138.70 & 389.33 & 0.723 & -636.92 & 914.32 \\
\hline EQ-5D/QALYs & 0.10114 & 0.09052 & 0.011207 & 0.00260 & $<0.0005$ & 0.00603 & 0.01638 \\
\hline
\end{tabular}

Note: *Controlling for baseline EQ-5D score, age, sex, type of operation.

Abbreviations: QALY, quality adjusted life year; GP, General Practitioner; A\&E, Accident and Emergency; EQ-5D, EuroQol 5 Dimension, 3 Level.

a WTP threshold of $£ 30,000$ (with costs per QALY gained of $£ 28,385$, and $£ 17,219$ respectively). When costs of equipment and supplies were at their highest level compared to open ( $£, 1477$ more expensive), the resulting ICER of $£ 34,690$ was marginally outside the cost-effective level; the turning point was $£ 1,424$. At its most expensive, where laparoscopic surgery achieved a reduction in hospital bed days costing only $£ 247$ compared to open, an ICER of $£ 70,332$ was realized. The threshold, where an ICER of $£ 30,000$ was achieved, was at a bed day cost reduction of $£ 699$; the mean cost reduction for bed days seen in the data exceeded this at $£ 897$.

Varying the estimated difference in QALY between the lower (0.00603) and upper (0.01638) 95\% confidence interval values had no effect on the cost-effectiveness at a WTP of $£ 30,000$, achieving ICER ranging from $£ 22,994$ to $£ 8,466$.

Staff operative costs were lower in the laparoscopic group, reflecting a shorter operation time by mean of 47 minutes, (which equates to a theatre staff and overhead cost of £169). Operation times may vary with surgeon experience and style, and have typically been shown to be higher in laparoscopic procedures than open. ${ }^{18}$ Given the mean difference in QALYs (0.011207) and costs (£139) observed in this study, laparoscopic operation time could be increased by 55 minutes (£197), ie, 8 minutes longer than open, with all other factors held constant, and still achieve an ICER $\leq £ 30,000$.

\section{Discussion}

This is the first cost-effectiveness analysis comparing laparoscopic and open colorectal surgery for colorectal resections to incorporate quality of life differences in the early postoperative recovery period. Whilst previous studies, based on longer follow-up periods, suggest no difference in outcomes between laparoscopic and open surgery, ${ }^{3-6}$ this study provides robust evidence of improved health-related quality of life outcomes associated with laparoscopy in the first 6 weeks post-surgery, and demonstrates the cost-effectiveness of that approach, compared to open methods. Improved health-related quality of life after laparoscopic surgery has been associated with less blood loss, better immune and inflammatory responses, less pain and analgesic requirements, faster postoperative recovery of bowel function, food intake, and physical activity. ${ }^{17,18}$

Quality of life in this study was measured earlier in the recovery period and more intensively than in most other

Table 3 Group comparison of operation time and length of hospital stay

\begin{tabular}{|c|c|c|c|c|c|c|c|c|c|c|}
\hline & \multicolumn{3}{|c|}{ Laparoscopic } & \multicolumn{3}{|c|}{ Open } & \multicolumn{3}{|c|}{$\begin{array}{l}\text { Difference } \\
\text { (open - laparoscopic) }\end{array}$} & \multirow{2}{*}{$\begin{array}{l}\text { Mann-Whitney } \\
U \text { test } \\
P\end{array}$} \\
\hline & $n$ & Mean & $\overline{S D}$ & $n$ & Mean & $\overline{\text { SD }}$ & Mean & $\begin{array}{l}95 \% \\
\text { inter }\end{array}$ & $\begin{array}{l}\text { confidence } \\
\text { vals }\end{array}$ & \\
\hline Duration of surgery (minutes) & 49 & 108.3 & 35.4 & 12 & 155.4 & 67.8 & 47.2 & 3.4 & 90.9 & 0.0071 \\
\hline Length of hospital stay (days) & 64 & 4.00 & 2.64 & 27 & 6.15 & 2.52 & 2.15 & 0.97 & 3.33 & $<0.0005$ \\
\hline
\end{tabular}

Abbreviation: SD, standard deviation. 


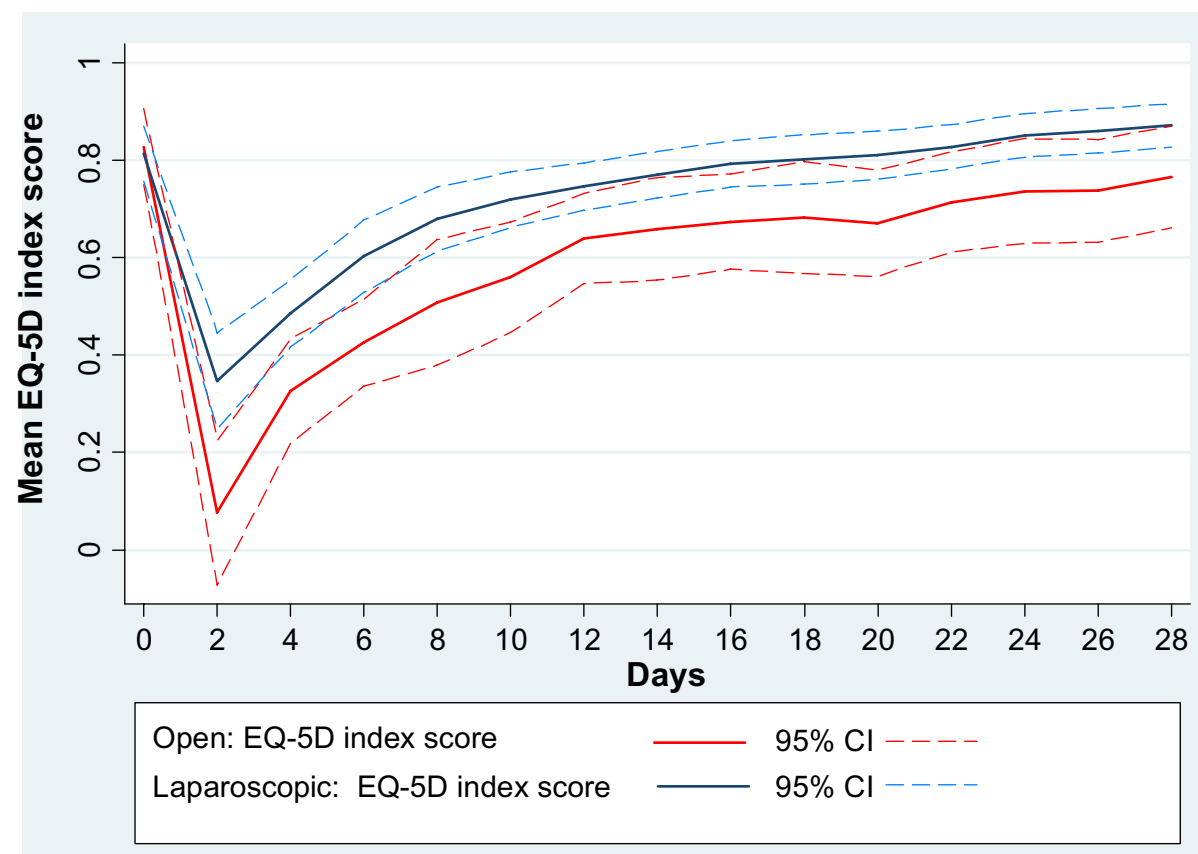

Figure I Mean EQ-5D index scores at baseline and each follow up point.

Note: Based on complete case data for patients with cancer or polyps.

Abbreviations: $\mathrm{Cl}$, confidence interval; EQ-5D, EuroQol 5 Dimension, 3 Level.

studies comparing laparoscopic and open methods for colorectal surgery. Moreover, the EQ-5D instrument was used to enable the calculation of QALYs so that a cost-effectiveness analysis could be undertaken. Health-related quality of life in most other studies has been measured using a variety of different generic and disease-specific instruments, 4,5 and at later time points post-surgery, making direct comparison of the findings of different studies problematical.

The analysis reported in this paper is based on those patients with a diagnosis of cancer or polyps in a larger study

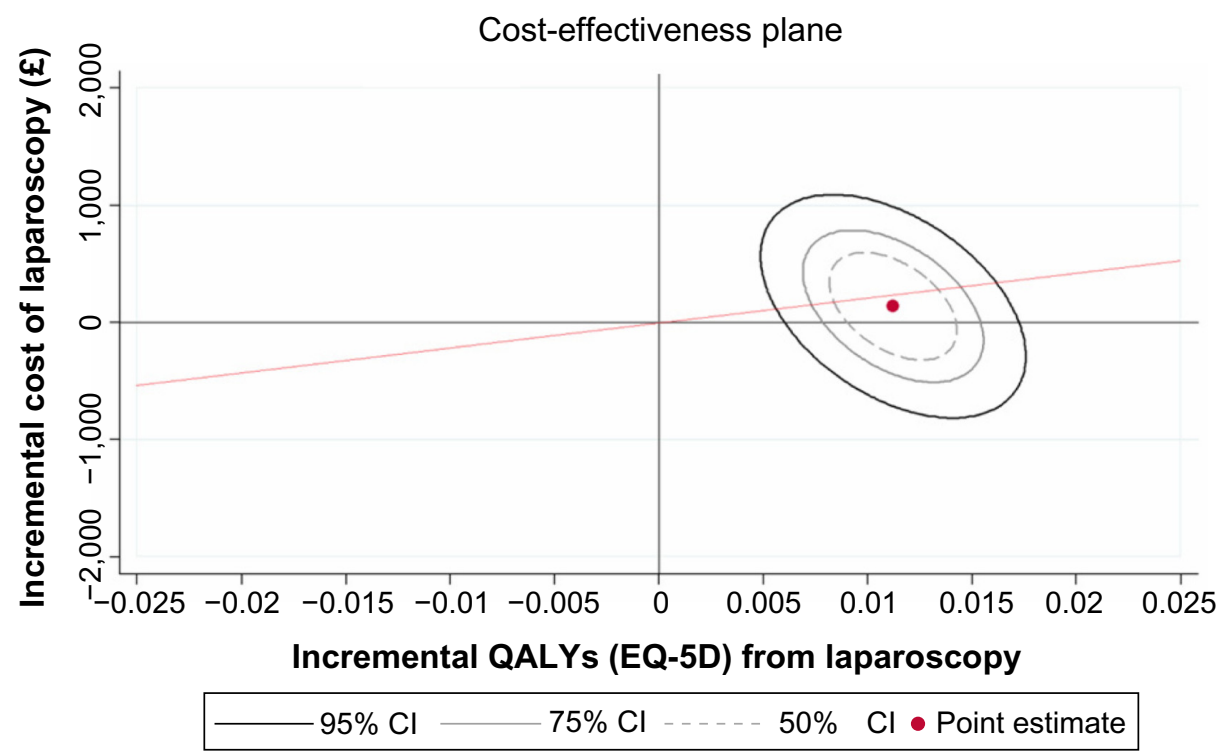

Figure 2 Cost-effectiveness plane.

Notes: The CEP is made up of four quadrants: lower right is the dominant quadrant, ie, laparoscopic surgery is less costly and more effective than open; upper left, laparoscopy is totally dominated, ie, it is less effective and more costly than open; upper right (and lower left) the situation is not clear cut because laparoscopy is more costly and more effective (less costly and less effective) than open. *Threshold line through the origin based on WTP $=£ 20,000$.

Abbreviations: CEP, cost-effectiveness plane; WTP, willingness-to-pay; Cl, confidence interval; EQ-5D, EuroQol 5 Dimension, 3 Level; QALY, quality adjusted life year. 


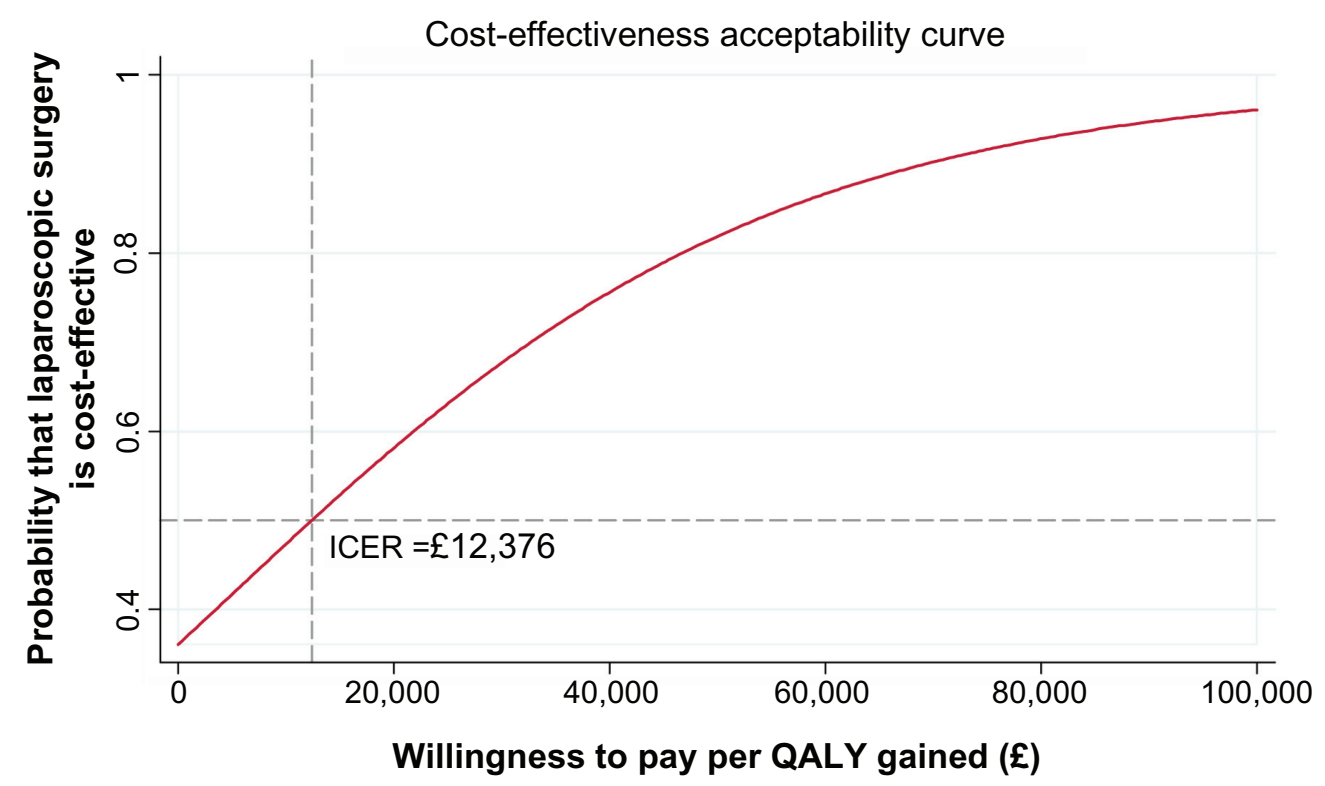

Figure 3 Cost-effectiveness acceptability curve.

Abbreviations: ICER, incremental cost-effectiveness ratio; QALY, quality adjusted life year.

of patients undergoing colorectal surgery at a district general hospital in England, ${ }^{9}$ ie, some $65 \%$ of the whole sample, ( $47 \%$ cancer, $18 \%$ polyps). Consistent with the parent study (which included those with a diagnosis other than cancer or polyps, and rectal resections) $)^{10}$ and other evidence, ${ }^{19,20}$ the overall costs of laparoscopic and open approaches for this subgroup were not significantly different, with higher operation costs (due to instrumentation) for the laparoscopic group largely offset by a shorter length of hospital stay.

The results demonstrate a significant QALY gain for laparoscopic surgery, compared to open, of 0.011207 at 28 days, which was similar to that observed for the whole sample in the parent study. ${ }^{7}$ This QALY gain exceeds that identified by the NICE technology assessment panel $(0.009-0.010)$ as being required in order to deem laparoscopic surgery costeffective for colorectal cancer. ${ }^{1,2}$ In the cost-effectiveness analysis, the point estimate cost per QALY gained was $£ 12,375$. The probabilistic approach to analyze the uncertainty demonstrated that the laparoscopic procedure was close to clear dominance over open surgery and cost-effective at a WTP below the current threshold set by NICE. ${ }^{8}$ The current guideline from $\mathrm{NICE}^{11}$ is that no fixed WTP will be enforced, although the 2004 guidance was that a plausible threshold is $£ 20,000-£ 30,000$. The sensitivity analysis showed the results to be relatively robust to variation in the main input variables. Only the cost of hospital stay was independently capable of shifting the ICER to a level above $£ 30,000$, but at bed day savings associated with laparoscopic below those recorded in this study. The deterministic sensitivity analysis showed laparoscopic surgery to be cost-effective with operation times up to 8 minutes longer than open.

This study has several limitations. The sample of cancer/ polyp patients was drawn from a larger study of all patients undergoing colorectal resection, and statistical power was lost because the numbers in this subset was small. The sample size was further eroded by the removal of rectal resections, which was done to avoid bias due to the disproportionate number of rectal resections in the open group. There is no reason to believe that the imbalance was due to any factor other than chance. However, the lack of randomization of patients to study groups is a drawback. Administrative staff, who were unconnected to the study were responsible for assigning patients to surgical teams at the point of referral by general practitioners. Allocation was based on pragmatic factors, such as availability of appointments, but this is not a good substitute for randomization.

The proportion of patients with a diagnosis of polyps, rather than cancer, was higher in the laparoscopic group than the open group (20.6\% versus $11.1 \%$ ). Since the postoperative recovery of patients with cancer is potentially different from that of patients with polyps, we tested whether the sample imbalance might affect the results, by adding a diagnosis variable (cancer versus polyps) to the regression modelling. Whilst this affected the coefficients by a very small amount, the diagnosis covariate was not significant $(P>0.5)$, indicating that it had no material effect on the findings.

The study was affected by missing data. Operative costs were based on observation and researchers had not been 
present during all surgeries. ${ }^{10}$ Some participants, particularly those with higher ASA grades at baseline, longer hospital stays and in higher intensity units, ${ }^{7}$ had not provided quality of life data. Even using multiple imputation, it was not possible to extend the analysis from 28 to 42 days, due to missing information. Multiple imputation was used in preference to a complete case analysis which would have reduced the sample size further. The impact of uncertainty in the sample data was accommodated in the sensitivity analysis and found to have little impact on the conclusions of the study. The results of the analysis using the imputed data sets were checked against those generated by a complete case analysis. The latter found laparoscopic surgery to be $£ 258$ more expensive, on average, than open (versus £139 using multiple imputation), and achieving a QALY gain of 0.013523 (versus 0.011207 ); ICER point estimate of $£ 19,106$ (versus £12,375).

The costs used were those collected at a base year of 2006. No adjustment for inflation has been made, and in nominal terms the results may overstate the significance of the findings. Since that time, the relative cost of the disposable instruments (a major item for the laparoscopic procedure) may have fallen due to increased uptake and advancements in technology. The cost of hospital stays (predominantly affecting the open group) has increased, but hospital policies for earlier discharge may have offset this to some extent. Rising staff costs will have affected both groups similarly. The study only focused on the first 6 weeks after surgery, and no subsequent follow-up of patients was conducted. This was because prior research had demonstrated no differences in survival or health-related quality of life in the longer term, ${ }^{1-6}$ and the research design deliberately focused on the early postoperative period where a gap in evidence had been identified. ${ }^{1,7}$

\section{Conclusion}

This study provides formal evidence of the cost-effectiveness of laparoscopic approaches based on quality of life gains, compared to open methods, in the early postoperative period. The findings support current guidelines that promote the use of laparoscopy where suitably trained surgeons are available. ${ }^{1}$ The National Training Programme LAPCO is enabling more hospitals to offer minimally invasive surgery options and patients to reap the benefits of faster recovery. ${ }^{21}$

\section{Acknowledgments}

John Stebbing and Christopher Marks provided valuable support and advice on the study design, data collection, and during patient recruitment, and their encouragement was greatly appreciated. We are also grateful to Karen Ballard, Yue Qiao, and Peter Williams for input into the quality of life, costing, and statistical aspects of the parent study.

\section{Disclosure}

The authors have no conflicts of interest to declare.

\section{References}

1. National Institute for Health and Clinical Excellence [homepage on the Internet]. Laparoscopic Surgery for Colorectal Cancer. NICE technology appraisal guidance 105, Aug 2006, revised 2009. Available from: http://www.nice.org.uk/guidance/TA105. Accessed July 1, 2014.

2. de Verteuil RM, Hernandez RA, Vale L, Aberdeen Health Technology Assessment Group. Economic evaluation of laparoscopic surgery for colorectal cancer. Int J Technol Assess Health Care. 2007;23(4): 464-472.

3. Murray A, Lourenco T, De Verteuile R, et al. Clinical effectiveness and cost-effectiveness of laparoscopic surgery for colorectal cancer: systematic review and economic evaluation. Health Technol Assess. 2006;10(45):1-141, iii-iv.

4. Dowson H, Cowie A, Ballard K, Gage H, Rockall T. Systematic review of quality of life following laparoscopic and open colorectal surgery. Colorectal Dis. 2008;10(8):757-768.

5. Bartels SA, Vlug MS, Ubbink DT, Bemelman WA. Quality of life after laparoscopic and open colorectal surgery: a systematic review. World $J$ Gastroenterol. 2010;16(40):5035-5041.

6. Fuji S, Ota M, Tchikawa Y, et al. Comparison of short, long-term surgical outcomes and mid-term health-related quality of life after laparoscopic and open resection for colorectal cancer: a case-matched control study. Int J Colorectal Dis. 2010;25(11):1311-1123.

7. Dowson HM, Ballard K, Gage H, Jackson D, Williams P, Rockall T. Quality of life in the first six weeks following laparoscopic and open colorectal surgery. Value Health. 2013;16(2):367-372.

8. National Institute for Health and Clinical Excellence [webpage on the Internet]. Guide to the methods of technological appraisal, NICE 2004. Available from: https://www.gov.uk/government/uploads/system/ uploads/attachment_data/file/191504/NICE_guide_to_the_methods_of_technology_appraisal.pdf. Accessed July 1, 2014.

9. Dowson H. The Cost Effectiveness of Laparoscopic Colorectal Surgery [MD thesis]. University of Surrey; 2009.

10. Dowson HM, Gage H, Jackson D, Qiao Y, Williams P, Rockall TA. Laparoscopic and open colorectal surgery: a prospective cost analysis. Colorectal Dis. 2012;14(11):1424-1430.

11. National Institute for Health and Clinical Excellence [webpage on the Internet]. NICE implementation uptake report: laparoscopic surgery for colorectal cancer, NICE 2010. Available from: http://www.nice. org.uk/guidance/ta105/resources/nice-implementation-uptake-reports. Accessed July 1, 2014.

12. Engel A. Editor's choice. Colorectal Dis. 2012;14(7):1473-1478.

13. Brazier J, Jones N, Kind P. Testing the validity of the Euroqol and comparing it with the SF-36 health survey questionnaire. Qual Life Res. 1993;2(3):169-180.

14. Parkin D, Rice N, Jacoby A, Doughty J. Use of a visual analogue scale in a daily patient diary: modelling cross sectional time series on healthrelated quality of life. Soc Sci Med. 2004;59(2):351-360.

15. Euroqol Group [homepage on the Internet]. Available from: http://www. euroqol.org/. Accessed July 1, 2014.

16. Little RJA, Rubin DB. Statistical Analysis with Missing Data. 2nd ed. New York: John Wiley; 2002.

17. Braga M, Vignali A, Zuliani W, Frasson M, DiSerio C, DiCarlo V. Laparoscopic versus open colorectal surgery. Ann Surg. 2005;242(6): 890-896. 
18. Abrahams NS, Young JM, Solomon MJ. Meta-analysis of short term outcomes after laparoscopic resection for colorectal cancer. Br J Surg. 2004;91(9):1111-1124.

19. Dowson HM, Huang A, Soon Y, Gage H, Lovell DP, Rockall TA. Systematic review of the costs of laparoscopic colorectal surgery. Dis Colon Rectum. 2007;50(6):908-919.

20. Reza MM, Blasco JA, Andradas E, Canteri R, Mayol J. Systematic review of laparoscopic versus open surgery for colorectal cancer. $\mathrm{Br} \mathrm{J}$ Surg. 2006;93(8):921-928.
21. National training programme in laparoscopic colorectal surgery [homepage on the Internet]. Proportion of Colorectal Resections Undertaken Laparoscopically in England. Available from: http://www. lapco.nhs.uk/activity-latest-HES-data.php. Accessed August 1, 2013.

\section{Publish your work in this journal}

ClinicoEconomics \& Outcomes Research is an international, peerreviewed open-access journal focusing on Health Technology Assessment, Pharmacoeconomics and Outcomes Research in the areas of diagnosis, medical devices, and clinical, surgical and pharmacological intervention. The economic impact of health policy and health systems organization also constitute important areas of coverage. The manuscript management system is completely online and includes a very quick and fair peer-review system, which is all easy to use. Visit http://www.dovepress.com/testimonials.php to read real quotes from published authors.

Submit your manuscript here: http://www.dovepress.com/clinicoeconomics-and-outcomes-research-journal 